\title{
EXPECTATIVAS DOS ALUNOS DE ENFERMAGEM FRENTE AO PRIMEIRO ESTÁGIO EM HOSPITAL .
}

\author{
NURSING STUDENTS EXPECTATIONS REGARDING \\ THEIR INICIAL HOSPITAL TRAINING .
}

\author{
Maria Dalva de Barros Carvalho * \\ Sandra Marisa Pelloso* \\ Elizabeth A.S.S. Valsecchi** \\ Jorséli A.H. Coimbra***
}

CARVAlHO, M.D. de B. et al. Expectativas dos alunos de enfermagem frente ao primeiro estágio em hospital. Rev.Esc.Enf.USP, v.33, n.2. p. 200-6, jun. 1999.

\section{RESUMO}

A primeira vivência em estágio hospitalar pode gerar tensões e ansiedades. Esses sentimentos interferem negativamente no processo ensino - aprendizagem. O objetivo deste trabalho foi conhecer as expectativas dos alunos de Fundamentos de Enfermagens. II acerca- do primeiro estágio hospitalar. Foram sujeitos desta pesquisa alunos do $2^{\circ}$ ano do Curso de Enfermagem da. Universidade Estadual de Maringá - Pr. Os alunos revelaram, atitudes de ansiedade quanto a procedimentos técnicos, relacionamento com o paciente e avaliação. Ao refletir sobre esses aspectos, o docente pode favorecer a eficácia do ensino e a humanização na formação.

UNITERMOS : Ansiedade. Ensino-aprendizagem. Estágio supervisionado.

\section{ABSTRACT}

The first experience in hospital training may create tensions and anxieties. These feelings interfere negatively in the teaching - learning process. The aim of this paper was to investigate the expectations of Nursing Fundamentals II students regarding their initial hospital training. Second-year students of the Nursing Course offered by Universidade Estadual de Maringá. ( state of Paraná. , Brazil,) were chosen as subjects of this investigation. The students revealed a. state of anxiety when. confronting technical procedures, relationship with patients and evoluation. By reflecting on these aspects instructor the may increase the teaching-learning efficiency and humanize the professional training.

UNITERMS: Anxiety. Teaching-learning. Supervised professional training.

O currículo de Enfermagem estabelece o ciclo básico. englobando disciplinas das áreas biológicas e humanas. e o tronco profissionalizante com matérias afins. O tronco profissionalizante é aquele em que o aluno desenvolve todo o atendimento de enfermagem ao paciente e presta cuidados individualizados, fundamentado nas necessidades básicas de saúde física e mental.

A complexidade do currículo evidencia-se a partir do segundo ano, quando ocorre concomitantemente o ciclo básico e o profissionalizante. Nesta etapa, inicia-se o aprendizado prático em estágio supervisionado.

Na Universidade Estadual de Maringá ele ocorre no segundo ano, quando o acadêmico inicia seu estágio em Fundamentos de Enfermagem II, realizado em campo hospitalar.

Andrade; Ferreira Lima apud ANDRADE at al ( 1989), entendem o estágio curricular "como a etapa de aplicação do conhecimento reflexivo e do aperfeiçoamento de habilidades numa situação real; é o momentum de junção do saber com o fazer, que

\footnotetext{
* Enfermeira . Dr ${ }^{a}$ em Enfermagem, Prof ${ }^{a}$ Adjunto da Universidade Estadual de Maringá. - PR. Enfermeira

** Mestranda em Enfermagem, Prof Assistente da Universidade Estadual de Maringá - PR. Enfermeira.

*** Mestranda em Enfermagem, Prof' Auxiliar da Universidade Estadual de Maringá - .PR.
} 
conduzirá suas dúvidas a um agir profissional mais consciente, crítico e criativo".

Currículos complexos, estágios complexos, seres humanos complexos geram expectativas complexas, podendo desencadear conflitos tanto para alunos como para professores neste percalço. $\mathrm{O}$ académico, nesta etapa do curso, é jovem, inexperiente, imaturo, com pouca ou nenhuma convivência com a dor, o sofrimento e a morte. Por outro lado, o hospital sempre foi e será palco das mais variadas emoções.

A entrada brusca dos alunos numa situação desconhecida é um fator desencadeante de tensões e ansiedades. Estes tipos de sentimento interferem de modo negativo no aprendizado, sendo imprescindivel que o docente que atua diretamente em campo de estágio, principalmente no estágio inicial, ou seja, aquele que vai dar o "debut" do aluno em campo de estágio, incorpore atitudes de compreensão do outro.

ROGERS apud BORDENAVE (1986) afirma que "... o fim da educação é facilitar e a aprendizagem reside em certas qualidades de atitude que existem na relação pessoal entre o facilitador e o aprendiz".

De acordo com HEIDEGGER (1995), "relacionar - se de uma maneira envolvente e significativa com pessoas implica em levar em consideração o outro. Significa possibilitar ao outro assumir seus próprios caminhos, amadurecer e encontrar-se consigo mesmo".

As interações aluno/aluno, aluno/professor, aluno/equipe de saúde, aluno/funcionário fazem parte da relação interpessoal que é o alicerce que oportuniza a aprendizagem. Neste contexto, a eficácia da aprendizagem se dá quando há uma sólida reação interpessoal.

Neste universo de variáveis tão complexas acontece o estágio de Fundamentos de Enfermagem II, no qual há um grande caminho a ser percorrido que gera ansiedades e por outro lado, não significa ser uma situação confortável para o professor, mediador que conduz A eficácia do processo ensino aprendizagem. Cumpre ressaltar outro aspecto que, se não agrava, também não facilita a aprendizagem, que é o fato de o estágio ocorrer em hospitais privados. Isto significa que, na interface do relacionamento aluno/enfermeiro, profissional de saúde, o aluno depara-se com auxiliares e atendentes de enfermagem. Estes profissionais e ocupacionais que atuam mais diretamente com o paciente, via de regra são os que estão mais em contato com o aluno e muitas vezes não estão preparados para um trabalho em equipe. A necessidade de desenvolver tarefas, As vezes, se choca com as necessidades dos alunos para o aprendizado e disso pode advir o conflito.
Tendo em vista circunstâncias tão diversas e conflituosas que envolvem o primeiro estágio do acadêmico de enfermagem em hospital, este trabalho tem por objetivo conhecer as expectativas dos alunos de Fundamentos de Enfermagem II da Universidade Estadual de Maringá, acerca do estágio hospitalar, antes do seu início.

\section{MATERIAL E MÉTODOS}

Este estudo caracteriza-se por uma abordagem qualitativa. Para MINAYO ( 1993) a abordagem qualitativa "incorpora a questão do significado e da intencionalidade como inerentes aos atos humanos..." Deste modo procurou-se compreender sob a perspectiva do aluno, como o primeiro estágio hospitalar se apresenta a ele no início de sua formação prática. Quais as expectativas que têm, quando do enfrentamento de uma situação prática na sua formação global.

Foram sujeitos desta pesquisa todos os alunos do $2^{\circ}$ ano do curso de Enfermagem da Universidade Estadual de Maringá que iniciariam o estágio supervisionado em hospitais, na disciplina de Fundamentos de Enfermagem II no primeiro semestre e 1996, perfazendo um total e 22 alunos. O instrumento e coleta e dados foi um questionário com questões fechadas e abertas, que permitiram caracterizar a população e extrair dados de análise pertinentes ao estudo.

Os questionários foram lidos e analisados, o que permitiu a identificação de temas comuns. Em uma fase posterior de análise, os temas comuns foram aglutinados em categorias mais abrangentes.

Como resultado final da análise obtivemos as seguintes categorias: ansiedade; período de preparação para o estágio e relacionamento com a equipe.

\section{ANÁLISE DOS DADOS}

\section{CARACTERIZAÇÃo DOS SUJEITOS}

Dos 22 alunos que respoderam o questionário, $40.9 \%$ estão na faixa etária e 18 - 19 anos e 36,4\%, na faixa de 20 - 21 anos. São jovens, o que pressupõe inexperiência para enfrentar situações mais dificeis.

Por sua vez, com relação ao sexo, 95,5\% são do sexo feminino. Vários autores já descreveram a Enfermagem como profissão predominantemente feminina.

Com relação ao ano de ingresso na Universidade, $68,2 \%$ dos alunos ingressaram em 
1995. Um dado importante é que $22,7 \%$ dos alunos são repetentes, o que significa já terem cursado a disciplina de Fundamentos de Enfermagem II. Não fizeram curso de auxiliar de enfermagem ou similares $95,5 \%$ dos alunos. Este fato nos mostra que, em Maringá, os alunos que procuram o curso de Enfermagem não são profissionais ou ocupacionais da área.

Em outro dado que se refere à experiência em ambiente hospitalar, 59,1\% responderam que sim, ou seja, apresentam experiência, e esta experiência diz respeito a estágios extracurriculares. Já 40,9\% responderam que não possuem experiência alguma.

\section{CATEGORIAS}

\section{A ANSIEDADE}

\subsection{Procedimentos técnicos}

Dos alunos entrevistados, 81,8\% expressaram ansiedade com reação aos procedimentos técnicos: o medo e errar na execução de técnica, e com isso provocar prejuízos ao paciente sob seus cuidados. Esta condição precisa ser entendida como natural pelo professor. A competência técnica e a capacidade e resolver problemas fornecem ao aluno segurança para agir. Esta competência técnica inexiste nesta primeira experiência do estudante. Sua ansiedade será diminuída se contar com a presença constante do surpevisor, com seu apoio e sua intervenção quando necessária.

Ainda com relação aos procedimentos técnicos, um dado que chamou a atenção foi a especificação sobre cuidados de higiene. Os acadêmicos, ao mencionarem este aspecto, deixam transparecer as dificuldades que enfrentam ao invadirem a privacidade dos pacientes. Este é um ponto delicado que deve ser levado em consideração pelo professor. E uma questão ética tanto com relação ao paciente quanto ao aluno.

Preparar tecnicamente o acadêmico para esta atividade, por si só não é suficiente. Necessário se faz a formação de grupos para troca de experiências, reflexões, leituras, de modo a prepará-los para enfrentar esse tipo de situação.

\subsection{Relacionamento com o paciente}

A ansiedade expressa pelos alunos sobre a relação com o paciente foi outro dado que se destacou. Os alunos não especificaram as dificuldades que poderiam ter em relação ao contato com o paciente. Deixaram, entrever todavia, que a maior delas é a comunicação. Como a maioria dos acadêmicos é jovem, parece-nos natural essa dificuldade. Há, porém, que atentar para ela. O problema da comunicação envolve a empatia, sensibilidade para o mundo interior, e significação pessoal privada de outra pessoa (ASPY, 1972). A empatia precisa estar presente também na relação professor aluno como um modo de ajudar o acadêmico a ver mais claro o que venha a ser uma relação interpessoal positiva. Segundo DIXON \& MORSE apud ASPY (1972), "o aspecto importante da empatia, tal como o reconhecemos no ensino, é fenômeno altamente interpessoal com sujeito e objeto concentrados numa resposta mútua".

Essa relação interpessoal, dinâmica, concentrada numa resposta mútua, possibilita ao professor não se contentar apenas com mudanças no conhecimento do aluno, mas almejar sempre mudanças no comportamento, já que conhecimento por si só não produz comportamento desejado.

\subsection{Avaliação}

A avaliação, segundo os acadêmicos, revelou ser uma fonte de ansiedade. Mostraram-se preocupados com a "nota", por não saberem exatamente quais os objetivos a serem alcançados, se seus objetivos coincidem com os do professor. Estes tipos de questionamento revelam as experiências muitas vezes desagradáveis pelas quais já passaram durante a vida escoar. A questão da avaliação é complexa e precisa ser refletida e processada com cuidados adequados. Ela, via e regra, traduz as relações aluno - professor. Deverá haver uma correlação entre avaliação e objetivos propostos, para que não aconteça uma escolha arbritária de instrumento de avaliação. Em campo de estágio os objetivos e os critérios de avaliação precisam ser bem explicitados. $O$ aluno necessita ser esclarecido e orientado para compreender que estas atividades são inerentes e necessárias ao seu preparo profissional. É importante destacar também que a educação é um processo e não um produto e, portanto, as expectativas o professor com relação ao desempenho o aluno têm de ser adequadas à realidade o nível em que ele se encontra.

De acordo com FERMIN apud BORDENAVE (1986), "emitimos constantemente juizo sobre alguma coisa, pessoas, valores. A escola e nosso tempo deve urgentemente dirigir seus esforços no sentido e sistematizar, tecnificar e humanizar o processo e avaliação".

Refletir sobre estas questões e dialogar sobre elas com os alunos pode colaborar para diminuir a ansiedade e facilitar o aprendizado. 


\subsection{Outras ansiedades}

Os acadêmicos revelaram outras ansiedades como o medo de sua reação pessoal diante das situações diferentes.

Entendemos esta ansiedade como uma reação natural a qualquer ser humano quando em situação desconhecida. Aliás, nós enfermeiros temos reações diferentes diante de diferentes situações. É até bastante comum o enfermeiro ter dificuldade de trabalhar com pacientes em fase final, com pacientes com problemas de náuseas e emese, etc... Salientamos aqui a necessidade de o professor compreender e trabalhar estas dificuldades nos alunos, para que possam ser superadas ou vivenciadas com mais equilíbrio. Mais uma vez a questão da relação interpessoal, da empatia como um mediador e estimulador da aprendizagem se destaca.

\subsection{A não ansiedade}

Apenas três alunos não expressaram ansiedade com relação ao primeiro estágio hospitaar. Um aluno argumentou que é natural a ansiedade pela novidade, mas que isso não significava medo, insegurança, temor, ou seja, algo que em princípio dificultasse ou atrapalhasse seu desempenho. Dois alunos relataram que a ansiedade inexiste, pois, por já haverem cursado a disciplina, não se sentiam em situação tão desconhecida.

É interessante notar que estes alunos que correspondem a $40 \%$ do total de reprovados. Isto sugere que a maioria dos acadêmicos que já tinha realizado o estágio demonstrou as mesmas ansiedades dos iniciantes. Este dado revela o cuidado que o docente deve dispender para com todos os acadêmicos, no sentido de diminuir tensões e ansiedades, promovendo um ambiente propício para que o aprendizado se processe.

\section{PERÍODO DE PREPARAÇÃo PARA O ESTÁGIO}

Os alunos se dividiram com relação a este aspecto: $40,0 \%$ responderam que o período de preparação para o estágio, ou seja, aulas em laboratório de ensino de enfermagem, aulas teóricas, monitorias, foram suficientes e $59,1 \%$ entenderam que este período não foi suficiente para dirimir as dúvidas e diminuir a ansiedade para o início das atividades em campo de estágio hospitalar.

Observou-se aqui. o seguinte: o porcentual dos que acharam que este periodo não foi suficiente é menor que o porcentual que admitiu as mais variadas formas de ansiedade antes do inicio do estágio. Pode-se inferir pelos dados que os acadêmicos entendem a preparação para o estágio apenas sob o aspecto técnico. Há que se questionar se isto realmente vem ocorrendo no período. Evidencia-se uma ênfase no aspecto técnico em detrimento do humano, das relações interpessoais, da comunicação, etc...

\section{O RELACIONAMENTO DE EQUIPE}

O trabalho de enfermagem é uma atividade que essencialmente se faz em equipe. A Enfermagem está em contato com o paciente durante 24 horas por dia. A qualidade de seu desempenho depende basicamente da articulação do enfermeiro com outros membros da equipe de saúde.

O aluno de enfermagem, ao iniciar o estágio hospitalar, entrará em contato com a equipe médica e de enfermagem principalmente. Além disso, passará a conviver mais intensamente com o docente supervisor e os próprios colegas. Julgamos então conveniente conhecer suas expectativas perante esses relacionamentos

\subsection{0 docente supervisor}

A maior ansiedade dos alunos com reação ao docente supervisor diz respeito à compreensão. Eles esperam que o professor seja calmo e compreensivo; que entenda suas falhas por estarem começando; que comentem seus erros particularmente para que eles não se repitam.

Outro aspecto salientado foi a questão novamente da avaliação, que parece ser um grande problema para os alunos. Salientaram também que esperam um acompanhamento direto do supervisor, como garantia de que suas inseguranças não se transformem em erros e em prejuízos para o paciente.

A questão do comportamento ético do professor também foi abordada. Esperam que o professor não os constranja, não os advirta em público e nem comente seus erros com outros membros da equipe. Houve destaque também para a figura do professor orientador, estimulador, aquele que faça compreender que ele, o aluno, é capaz.

Porém, um dado que apareceu uma única vez nos chamou bastante a atenção. Apenas um aluno se referiu à expectativa de que o professor seja um bom transmissor de conhecimentos.

Pelos dados levantados, acreditamos que na expectativa dos alunos, a figura do professor se reveste de um caráter humanista. $O$ professor competente sob o aspecto técnico, mas também, imparcial, humano, compreensivo, orientador, justo, parece ser a figura idealizada e desejada pelos alunos. 
Se a função da Enfermagem é o cuidado ao cliente; se este cuidado está envolto numa relação humana, empática, é preciso que os acadêmicos vivenciem esta relação, principalmente com o professor, na sua fase de formação, para que possam desenvolvê-la no seu dia - a - dia como profissionais.

\subsection{A equipe médica}

As expectativas dos alunos com relação à equipe médica estão em grande parte voltadas para a questão da multidisciplinaridade. Esperam da equipe médica cooperação, troca de experiências e também transmissão de conhecimentos. Todavia, um dado que se evidenciou com muita força foi a questão do respeito para com o aluno de enfermagem e a sua não - discriminação.

O problema da relação de poder, da não valorização da Enfermagem dentro da equipe de saúde precisa ser enfrentado de modo mais incisivo. Esta preocupação já tão evidente na fase inicial da formação do enfermeiro pode vir a ser um grande empecilho para seu desempenho profissional.

\subsection{Os próprios colegas}

Com relação a este aspecto, a grande maioria dos acadêmicos espera dos próprios colegas um trabalho de equipe, coeso. $\mathrm{O}$ respeito mútuo e o companheirismo devem ser, na visão dos alunos, a moa propulsora e reguladora da convivência. Alem disso, a troca de experiências, a união, o apoio, a não-competição, aliados ao sentimento de amizade, solidariedade e confiança completam o quadro das reações aluno/aluno em campo de estágio.

É natural que em situações adversas ou desconhecidas os pares se unam como forma de criar força, confiança e estímulo para a realização de uma tarefa. No nosso entender, o professor supervisor poderia então estimular a manutenção de um ambiente agradável, cooperativo não competitivo, onde o aluno, em se relacionando com indivíduos diferentes, com características diversas, poderia perceber os fatores que influenciam o comportamento humano. Seria o aprender a fazer, fazendo.

MANZOLLI (1985) diz que "a formação do enfermeiro deve enfatizar a compreensão do comportamento humano a partir do auto-conhecimento e do conhecimento integral do paciente". Para atingir esse objetivo é preciso que o acadêmico treine as relações a começar com seus pares. E o professor tem uma grande parcela de responsabilidade, propiciando ou não condições para que este aprendizado se efetue.

\subsection{0 funcionário do setor}

O funcionário do setor, como parte integrante da equipe pode ser um fator desencadeante de tensões e ansiedades. O acadêmico, ao iniciar seu estágio, querendo ou não, de certo modo acaba quebrando a rotina hospitalar. Isto afeta mais diretamente o funcionário. Antes do ingresso em estágio, ele já tem consciência desta situação. Tanto é verdade que sua expectativa maior perante o relacionamento com os funcionários é de que haja uma boa interação pessoal. Os alunos esperam que o fato de serem iniciantes seja levado em consideração por esta fatia de trabalhadores da equipe de enfermagem. O respeito e cooperação mútuos, o auxilio no que se refere às rotinas hospitalares foram pontos bastante citados.

Aqui também a intervenção do docente é fundamental. O preparo do campo de estágio, envolvendo orientações aos funcionários e alunos; a presença constante; a capacidade de observação e detecção de conflitos; a imparcialidade e serenidade na resolução de problemas de relacionamento interpessoal são fatores imprescindiveis para um desempenho acadêmico eficaz, uma assistência de qualidade e uma convivência em grupo satisfatória.

\section{CONSIDERAÇÕES FINAIS}

O objetivo deste trabalho foi conhecer as expectativas dos acadêmicos que iniciariam o seu primeiro estágio em campo hospitalar. Os resultados obtidos possibilitam algumas reflexões. A primeira delas refere-se ao ensino e desenvolvimento de procedimentos técnicos. A primeira vista, não se revela toda a complexidade que envolve a situação. Não se discute a necessidade de desenvolver a competência técnica do acadêmico de enfermagem, que será a garantia de um trabalho seguro e eficaz como profissional. Porém há que atentar para o desenvolvimento de habilidades não só no agir, mas também no sentir. Se a função precípua do enfermeiro é o cuidado ao ser humano, é necessário enfatizar a compreensão do outro, o respeito ao outro. Estas habilidades têm um caráter ético e de cidadania, caráter este que se revela no respeito ao paciente, no respeito ao seu direito de tomar decisões quanto à sua saúde, no não-arbítrio, na nãoviolência.

A formação essencialmente técnica, não humanista, corre o risco de chegar aos extremos, como na fala de ALVES (1993) "um técnico de boca aberta é mais perigoso para a democracia que uma urna de boca fechada". 
Outro ponto que está intimamente ligado ao anterior é a questão do relacionamento do aluno com a equipe de saúde. Aqui consideramos o papel do docente supervisor de extrema importância. Ele deverá ser o elo de aglutinação dessas relações. $O$ alunado espera dele uma atitude de competência, de compreensão, de ética e de bom-senso. Estas atitudes facilitam o processo de aprendizagem, diminuindo atritos e ansiedades.

A questão da avaliação, que se revelou um gerador de ansiedades, é um ponto extremamente polêmico. Ela exerce um poderoso efeito sobre a aprendizagem. Acreditamos porém que, se os objetivos do estágio curricular forem apresentados e explicitados aos acadêmicos, se a avaliação tiver um caráter formativo e se realizar periodicamente para que o aluno tome ciência o seu ritmo de aprendizagem, as possibilidades de gerar conflitos serão diminuídas.

O primeiro estágio hospitalar o acadêmico de enfermagem pode ser a chave que abrirá ou fechará a porta de uma carreira. A figura do docente se destaca de forma significativa. Por ser ele no grupo o mais maduro, o mais preparado tecnicamente, o mais sensato, sua atitude e seu agir será o ponto de equilíbrio nas relações que o aluno iniciará no seu primeiro estágio hospitalar. Pode essa afirmativa parecer num primeiro momento, algo idealizado. Todavia esse estudo aponta que é essa atitude que dele se espera. E necessário também que o professor imponha limites à sua atuação. Não pode esquecer que o aprendizado está apenas começando, e deve ter claro para si mesmo as prioridades neste estágio inicial e não assuma todo o ensino como prerrogativa apenas sua. Seu papel aqui é extremamente importante e necessita ser valorizado. Ele será testado na sua competência, na sua ética e na sua formação humana.

\section{REFERÊNCIAS BIBLIOGRÁFICAS}

ALVES, R. Estórias de quem gosta de ensinar. São Paulo, Cortez, 1993.

ANDRADE, M.N. et al. Estágio curricular : avaliação de experiência. Rev. Bras. Enf., Brasília, ano 42, v. 1,2,3,4, p.27-41, jan/dez, 1989.

ASPY, D. Novas técnicas para humanizar a educação. São Paulo, Cultrix, 1972.

BORDENAVE, J. D. Estratégias de ensino - aprendizagem. 9. ed. Petrópolis/Rio de Janeiro, Vozes, 1986.

CARVALHO, V. L. Ensino de enfermagem e metodologia. 2. ed. Rio de Janeiro, Cultura Módica, 1979.

HEIDEGGER., M. Ser e tempo. parte I .5. ed. Petrópolis, Vozes, 1995.

MANZOLLI, M. C. Formação do enfermeiro: contribuições da psicologia. São Paulo, Sarvier, 1985.

MINAYO, M.C. O desafio do conhecimento: pesquisa qualitativa em saúde. 2. ed. São Paulo, Hucitec, 1993. 


\section{ANEXO}

\section{Questionário}

1. IDADE

2. SEXO - FEMININO ( ) MASCULINO ( )

3. ANO QUE INGRESSOU NA UNIVERSIDADE

4. VOCE TEM ALGUMA EXPERIÊNCIA NA AREA HOSPITALAR - ( ) SIM

( ) NÃO

QUAL

QUANTO TEMPO

5. VOCE JÁ CURSOU A DISCIPLINA DE FUNDAMENTOS DE ENFERMAGEM II () SIM ( ) NÃO

G. QUAL A SUA EXPECTATIVA DIANTE DO PRIMEIRO ESTÁGIO HOSPITALAR ?

7. QUAL A SUA EXPECTATIVA FRENTE AO RELACIONAMENTO COM O PACIENTE E COM AS OUTRAS PESSOAS DO HOSPITAL ?

8. VOCE SE ACHA PREPARADO PARA INICIAR O ESTÁGIO NO HOSPITAL ? 